\title{
The Conjugate Addition of tert-Butylmagnesium Chloride to 3,6-Disubstituted Pyridazines
}

\author{
I N G O L F C R O S L A N D \\ Organisk-kemisk Laboratorium, Polyteknisk Lareanstalt, Copenhagen, Denmark
}

\begin{abstract}
The addition of tert-butylmagnesium chloride to 3,6-dichloropyridazine and 3,6-dimethoxypyridazine was shown to involve a 1,4-addition of the Grignard reagent to yield the corresponding 4-tert-butyl3,6-disubstituted dihydropyridazine; apparently no dehydrogenated products were formed. The hydrolysis of the products was investigated.
\end{abstract}

In an attempt to synthesize alkylated pyridazine derivatives the reaction of 3,6-dichloro- and 3,6-dimethoxypyridazine with tert-butylmagnesium chloride was investigated.

The substitution of alkyl groups for halogens in the series of nitrogen heterocycles has been reported several times in the literature. The action of Grignard reagents on 2,3-dichloroquinoxaline ${ }^{1}$, 1-chloro-4-phenylphthalazine and 1,4-dichlorophthalazine ${ }^{2}$, cyanuric bromide ${ }^{3}$ and 2-bromoquinoline ${ }^{4}$ in all cases described leads to compounds in which the halogen is replaced by the alkyl group of the reagent. On the other hand, also conjugate addition has been encountered in many cases, for instance in the pyridine series ${ }^{5,6}$. The conjugate addition of butylmagnesium bromide to unsubstituted pyridazine has been reported 7 , although in this case only the dehydrogenated 4-alkylated compound was obtained, $c f$. below.

\section{RESULTS AND DISCUSSION}

The reactions investigated are illustrated by the chart. The only compounds formed were those derived from 1,4-additions of the Grignard reagent to the $\mathrm{C}=\mathrm{C}-\mathrm{C}=\mathrm{N}$ system (reaction $\mathrm{I} \rightarrow \mathrm{III}$ and $\mathrm{II} \rightarrow \mathrm{IV}$ ).

The position of the tert-butyl group on the pyridazine nucleus follows from the products obtained by the hydrolysis of IV. The formation of tert-butylsuccinic acid indicates that the 4-position was the point of attack of the nucleophilic alkyl group of the Grignard reagent. Although the analytical data of the unstable compound III are rather erratic, its structure is evidenced by its facile transformation into IV.

Cautious hydrolysis of IV affords VI in good yield. The elementary analysis indicates the loss of one methoxy group, presumably the one which is not subject to steric hindrance by the tert-butyl group. The hydrolysis of III follows a similar reaction path. More energetic hydrolysis of the dimethoxy compound

Acta Chem. Scand. 16 (1962) No. 8 


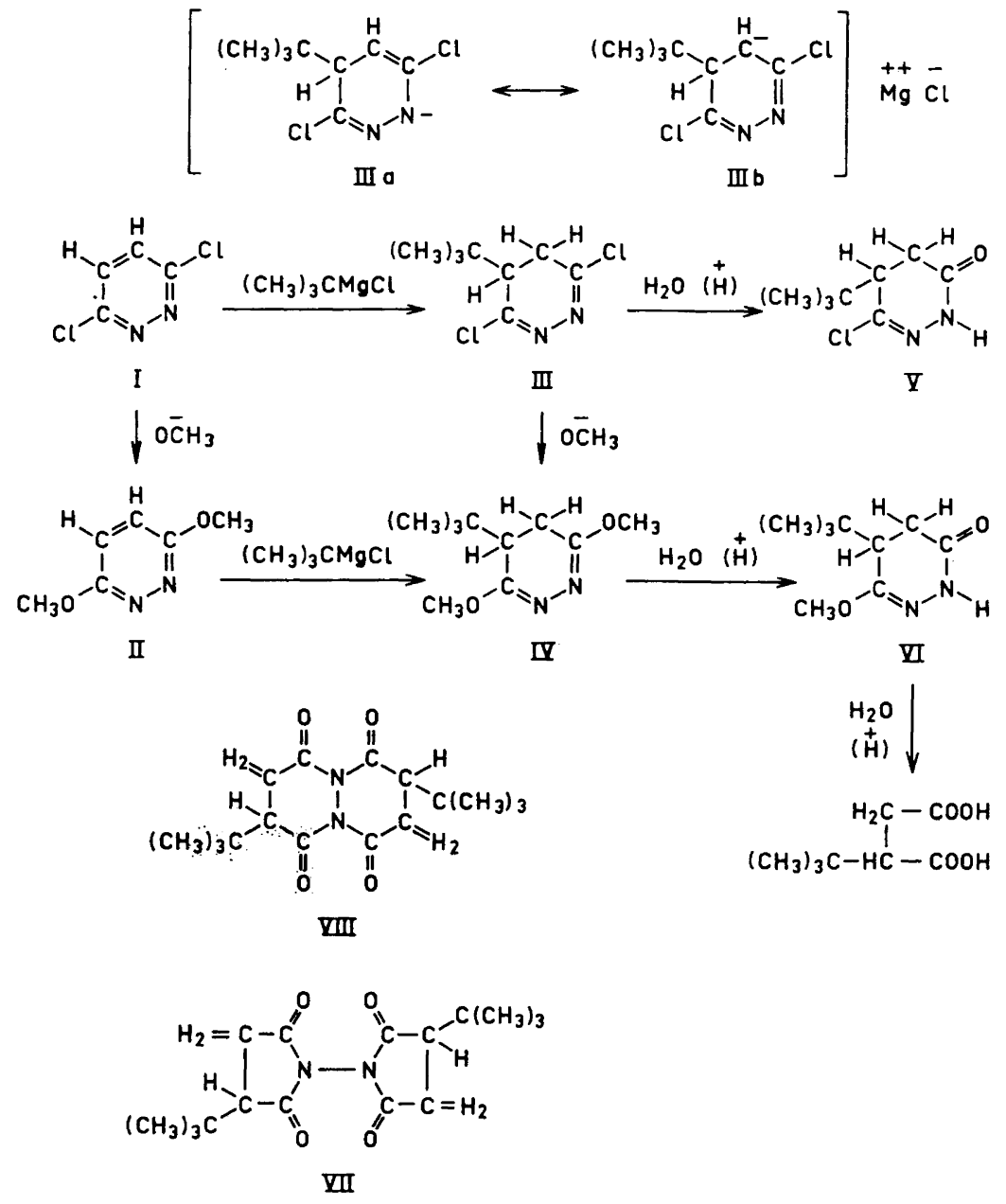

in some cases gives rise to the formation of a small amount of a compound, insoluble in both aqueous base and acid, besides the tert-butylsuccinic acid expected. On account of the empirical formula $\left(\mathrm{C}_{8} \mathrm{H}_{12} \mathrm{~N}_{2} \mathrm{O}_{2}\right)_{n}$ the compound may be formulated as VII or VIII (including many isomers), $c f$. the corresponding compounds in the succinic acid series ${ }^{8}$.

A characteristic and unexpected feature of the dihydro compounds III and IV is their resistance towards aromatization, which is in contrast to the readily occurring dehydrogenation encountered in, e.g., the pyridine series. This may be illustrated by the oxidation of the compounds formed by the 1,4-addition of Grignard reagents to the corresponding pyridine derivatives ${ }^{5}$ and by the catalytic dehydrogenation of 3,6-dimethyl-4,5-dihydropyridazine ${ }^{9}$. Whereas, in this laboratory, 3,6-dimethyl-4,5-dihydropyridazine has been readily dehydrogenated by the last mentioned method ${ }^{9}, 4$-tert-butyl-3,6-dimethoxy-4,5- 
dihydropyridazine (IV) failed to give the expected 4-tert-butyl-3,6-dimethoxypyridazine. Instead, IV was recovered unchanged. Preliminary investigations have shown that oxidizing agents such as bromine or acetyl peroxide did not bring about dehydrogenation of the dihydro compounds. The action of strong bases on any of the tautomeric forms of the dichloro compound III might be expected to afford dehydrohalogenated compounds. There is no supporting evidence that any reaction of this type has taken place. Even the Grignard reagent, present in excess during the synthesis of the dichloro compound III, does not effect elimination of hydrogen chloride. One could suggest that this fact is due to the partial negative charge of the magnesium chloride complex (IIIa $\leftrightarrow$ IIIb; also other structures may contribute to the resonance hybride) impeding the elimination of a proton. Apparently, this also applies to the reaction sequence III $\rightarrow$ IV, the action of methoxide ions resulting in substitution rather than elimination. The only evidence of the acidic properties of the dihydro compounds, as implicitely postulated by the formulation of the intermediate as IIIa and IIIb, is the heat of neutralization observed when the dichlorocompound III is added to a Grignard reagent. From this reaction mixture compound III may be regenerated in high yield by hydrolysis.

The reaction between the disubstituted pyridazines (I and III) and tertbutylmagnesium chloride is distinctly exothermic and takes place readily at the reflux temperature of ether. The exothermic nature of the reaction coupled with the characteristic resistance towards dehydrogenation is in accordance with the statement of Gilman ${ }^{6}$ regarding the addition of allylmagnesium bromide to aza-aromatic heterocycles: "All the more reactive heterocycles gave the product in the dihydro form, whereas the less reactive heterocycles yielded the product in the oxidized form".

All attempts to prepare dihydro compounds corresponding to III from 3,6-dichloropyridazine and other Grignard reagents such as, e.g., methylmagnesium iodide failed: When the ether extracts containing the reaction products were concentrated in vacuo, spontaneous decomposition took place with the evolution of hydrogen chloride.

The compounds formed by the reactions I $\rightarrow$ III and II $\rightarrow$ IV are suggested to be best formulated by the tautomers III and IV, respectively. Alder and Niklas ${ }^{10}$ have investigated the analogous tautomers of the 3,6-diphenyldihydropyridazines, and suggested that in this case the 4,5-dihydro tautomer is the product obtained by saponification of the corresponding $\mathrm{N}, \mathrm{N}^{\prime}$-di-(alkoxycarbonyl) compound.

Evidence as for the structure of compound IV may be gained from its NMR spectrum *. The spectrum of the pure liquid reveals two peaks (at $\delta 0.87 \mathrm{ppm}$ and $3.70 \mathrm{ppm}$, attributed to the hydrogens of the tert-butyl group and of the two methoxy groups, respectively) and a complex group of peaks between $\delta$ 2.1 and $2.7 \mathrm{ppm}$, which may be attributed to the configuration $\mathrm{CH}-\mathrm{CH}_{2}$ of the ring; any formulation involving $\mathrm{N}-\mathrm{H}$ bonds would not be expected to give peaks at the interval indicated.

\footnotetext{
* Spectra were taken in a Varian A-60 spectrometer at $60 \mathrm{Mc} / \mathrm{sec}$. using tetramethylsilane as an internal zero of reference. The author wishes to thank professor Børge Bak for helping interpret the spectra.
} 
When trifluoroacetic acid was used as a solvent the spectrum was changed only slightly with all the peaks shifted $(0.2-0.5 \mathrm{ppm})$ towards lower fields. The methoxy peak appeared split into a doublet as to be expected if one proton is attached to IV in the acid medium.

The hydrogen ratio determined by the intergral curve is 9.0:6.2:2.9 as compared to the theoretical values 9:6:3.

\section{EXPERIMENTAL,}

(All melting points are uncorrected).

4-tert-Butyl-3,6-dichloro-4,5-dihydropyridazine (III) (or tautomers). To a stirred solution of tert-butylmagnesium chloride, prepared from $12.5 \mathrm{~g}(0.51 \mathrm{~mole})$ of magnesium and $50 \mathrm{~g}(0.54 \mathrm{~mole})$ of tert-butyl chloride in $200 \mathrm{ml}$ of ether (duration of addition, $2 \mathrm{~h}, c f$. Organic Syntheses ${ }^{11}$ ), $50 \mathrm{~g}$ of 3,6-dichloropyridazine (I; prepared according to Mizzoni and Spoerri ${ }^{12}$ ) dissolved in $200 \mathrm{ml}$ of ether was slowly added.

A considerable amount of heat was liberated during the reaction as indicated by the lively reflux of the ether. The solution aquired a deep, reddish brown colour. The addition of the 3,6-dichloropyridazine solution was discontinued when further addition did not result in any reflux of the ether, indicating that all the Grignard reagent had been consumed. This required $41.4 \mathrm{~g}(0.278 \mathrm{~mole})$ of dichloropyridazine. After refluxing the solution for an additional $15 \mathrm{~min}$, the pyridazine-magnesium chloride complex was decomposed by adding $c a .60 \mathrm{ml}$ of a $20 \%$ aqueous ammonium chloride solution as fast as the reflux condenser would permit. Efficient stirring should be maintained, particularly during the addition of the last few $\mathrm{ml}$ of the ammonium chloride solution, since at this stage a slurry of salts precipitated. The addition of ammonium chloride solution was discontinued as soon as the ether solution became clear. The ether solution was separated by decantation. The salts were washed thoroughly with ether by decantation and the combined extracts immediately distilled, the bulk of the ether being removed at atmos. pheric pressure and the remaining ether at reduced pressure. The residue was distilled through a $20 \mathrm{~cm}$ Vigreux column $84-89^{\circ} / 1.5 \mathrm{~mm}$. A small forerun contained some un-

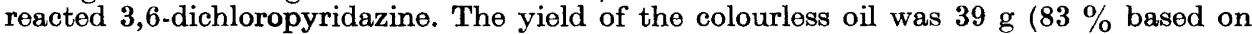
3,6-dichloropyridazine). A sample was redistilled for analysis, b.p. 80\%1.0 mm; (Found: C 47.40; $\mathrm{H}$ 6.16; Cl 31.50; $\mathrm{N}$ 13.62. Calc. for $\mathrm{C}_{8} \mathrm{H}_{12} \mathrm{Cl}_{2} \mathrm{~N}_{2}(207): \mathrm{C} 46.40 ; \mathrm{H}$ 5.85; Cl 34.25; N 13.52). The discrepancy may partly be due to the instability of the compound, which was stored at $-78^{\circ}$ before analysis. It decomposed with the evolution of hydrogen chloride into a black tar after $24 \mathrm{~h}$ at room temperature. Decomposition also occurred at $0^{\circ}$, however, at a lower rate, presumably also because of the semi-crystalline character at the lower temperature. Repeated attempts to recrystallyze the compound were unsuccessful. The compound was soluble in petroleum ether and diethyl ether, but insoluble in water and hydrochloric acid. The crystals melted below $41^{\circ}$.

3,6-Dimethoxy-4-tert-butyl-4,5-dihydropyridazine (or tautomers) (IV). The preparation from dimethoxypyridazine (prepared according to Druey et al. ${ }^{13}$ ) was quite similar to that of the corresponding dichloro compound, only the low solubility of the 3,6-dimethoxy. pyridazine in ether rendered the addition of the compound in this solvent impractible; it was therefore simply added portionwise without solvent. From $7.5 \mathrm{~g}$ of magnesium, $30 \mathrm{~g}$ of tert-butyl chloride and $20 \mathrm{~g}$ of 3,6-dimethoxypyridazine, $24 \mathrm{~g}(85 \%)$ of a colourless oil was obtained (b.p. $77^{\circ} / 0.5 \mathrm{~mm}, n_{\mathrm{D}}^{20}=1.4792$ ). A sample was redistilled for analysis: (Found: $\mathrm{C} 60.30 ; \mathrm{H} \mathrm{9.20;} \mathrm{N}$ 16.33. Calc. for $\mathrm{C}_{10} \mathrm{H}_{18} \mathrm{~N}_{2} \mathrm{O}_{2}$ (198) (IV): C 60.55; H 9.18; N 14.14) Repeated synthesis and fractionation gave a product showing the following values: C 60.55; H 9.07; N 16.24. Gas chromatographic analysis indicated the presence of a few percent of the dimethoxypyridazine, but this result cannot account for the high $\mathrm{N}$-values.

The same compound (IV) may also be prepared as follows: To a solution of sodium methoxide prepared from $7.7 \mathrm{~g}(0.33 \mathrm{~mole})$ of sodium and $150 \mathrm{ml}$ of methanol was added slowly $25 \mathrm{~g}(0.121 \mathrm{~mole})$ of 3,6-dichloro-4-tert-butyl-1,4-dihydropyridazine (III). The reaction was exothermic and sodium chloride precipitated. The solution was kept at $0^{\circ}$ overnight, the sodium chloride (12.7 $\mathrm{g} 0.22$ mole) filtered off and washed with methanol and the combined filtrates concentrated. Ether and water were added and the solution neu- 
tralized with acetic acid. The ether was separated and the aqueous phase extracted with ether. The combined extracts were concentrated and the residue distilled to yield a slightly yellow oil, the infra-red spectrum of which was identical with that of IV as prepared

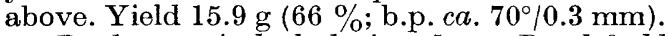

Products of hydrolysis. 5-tert-Butyl-6-chloro-2,3,4,5-tetrahydro-3-oxopyridazine (or isomer; V). $10 \mathrm{~g}$ of the dichloro compound (III) was added to a mixture of $25 \mathrm{ml}$ of $\mathrm{N}$ hydrochloric acid, $25 \mathrm{ml}$ of ethanol and $50 \mathrm{ml}$ of water and heated to reflux, the yellow solution turning green. The solution was immediately cooled in ice and an oil separated which subsequently crystallized to yield $4.9 \mathrm{~g}$ of greenish crystals, m.p. $108-129^{\circ}$. Three crystallizations from ligroin (b.p. $80-110^{\circ}$ ) yielded colourless leaflets, m.p. $140^{\circ}-141^{\circ}$. (Found: C 51.00; $\mathrm{H}$ 7.09; Cl 18.90; $\mathrm{N}$ 14.11. Calc. for $\mathrm{C}_{8} \mathrm{H}_{13} \mathrm{ClN}_{2} \mathrm{O}$ (188.5) (V): C 50.95; $\mathrm{H} 6.90 ; \mathrm{Cl} 18.83 ; \mathrm{N} 14.85)$.

5-tert-Butyl-6-methoxy-2,3,4,5-tetrahydro-3-oxopyridazine (or isomer; VI). $10 \mathrm{~g}$ of the dimethoxy compound (IV) were dissolved in $20 \mathrm{ml}$ of $4 \mathrm{~N}$ hydrochloric acid at $0^{\circ}$ and left at $c a .20^{\circ}$ for four days. The white, crystalline mass was filtered, washed with water and dried to yield $7.95 \mathrm{~g}$. One crystallization from ligroin (b.p. $110-140^{\circ}$ ) gave $6.7 \mathrm{~g}$ $\left(72 \%\right.$ ) of white crystals, m.p. $150-152^{\circ}$. A sample was crystallized twice from toluene, m.p. $151.5^{\circ}-152.5^{\circ}$. Found: $\mathrm{C} 58.70 ; \mathrm{H}$ 8.70; $\mathrm{N} 15.46$. Calc. for $\mathrm{C}_{9} \mathrm{H}_{16} \mathrm{~N}_{2} \mathrm{O}_{2}(184)$ (VI): C 58.63; H 8.82; N 15.20).

tert-Butylsuccinic acid and anhydride. $10 \mathrm{~g}$ of the dimethoxy compound (IV) dissolved in $150 \mathrm{ml}$ of $c a .6 \mathrm{~N}$ hydrochloric acid were refluxed for $20 \mathrm{~h}$, extracted 5 times with methylene chloride and the combined extracts concentrated in vacuo to yield $5.8 \mathrm{~g}$ of a viscous oil. Trituration with petroleum ether afforded $4.9 \mathrm{~g}$ of practically white crystals, m.p. $117-127^{\circ}$. A sample was crystallized three times from water and once from a mixture of toluene and ligroin (b.p. $110-140^{\circ}$ ) (6:4), m.p. 127-128.5 . (Authentic tert-butylsuccinic acid ${ }^{14}$ was kindly supplied by Dr. Munch-Petersen; m.p. $128-130^{\circ}$, mixed m.p. $128-129.5^{\circ}$, cf. $132^{\circ}$ (Wideqvist ${ }^{15}$ ).

tert-Butylsuccinic acid was refluxed for $10 \mathrm{~h}$ in excess of acetic anhydride, the acetic acid and reagent were removed in vacuo leaving an oil, which crystallized spontaneously. By three recrystallizations from ligroin, white crystals were obtained, m.p. $41.5-42^{\circ}$, (Found: $\mathrm{C} \mathrm{61.40;} \mathrm{H}$ 7.56. Calc. for $\mathrm{C}_{8} \mathrm{H}_{12} \mathrm{O}_{3}$ : C 61.50; $\mathrm{H}$ 7.75).

Hydrolysis of the dimethoxy compound (IV) in concentrated hydrochloric acid. Compound IV $(2 \mathrm{~g})$ was dissolved in $4 \mathrm{ml}$ of concentrated hydrochloric acid and kept at room temperature for $20 \mathrm{~h}$, then at $60^{\circ}$ for $4 \mathrm{~h}$ and finally refluxed for $4 \mathrm{~h}$. A little water was added to ensure complete dissolution of the hydrazine hydrochloride formed. A white precipitate was filtered off and recrystallized from ethanol, the yield amounting to $115 \mathrm{mg}$ of white crystals, m.p. $173-176^{\circ}$. An analytical specimen was recrystallized from ligrointoluene (1:1), m.p. $176^{\circ}-176.5^{\circ}$. (Found: $\mathrm{C} 62.60$ and $62.30 ; \mathrm{H} 7.95$ and $7.71 ; \mathrm{N} 9.20$. Calc. for $\mathrm{C}_{16} \mathrm{H}_{24} \mathrm{~N}_{2} \mathrm{O}_{4}$ (308) (cf. formula VII and VIII): C 62.31; H 7.86; N 9.08).

Analyses are by Mr. Preben Hansen, Microanalytical Division, The Chemical Laboratory, The University of Copenhagen.

\section{REFERENCES}

1. Ogg, R. A. and Bergstrom, F. W. J. Am. Chem. Soc. 53 (1931) 1846.

2. Mustafa, A., Harhash, A. H. and Saleh, A. A. S. J. Am. Chem. Soc. 82 (1960) 2735.

3. v. Meyer, E. and Näbe, F. J. prakt. Chem. [2] 82 (1910) 521.

4. Gilman, H., Eisch, J. and Soddy, T. S. J. Am. Chem. Soc. 81 (1959) 4000.

5. Lukes, R. and Kuthan, J. Collection Czechoslov. Chem. Communs. 26 (1961) 1422.

6. Gilman, H., Eisch, J. and Soddy, T. S. J. Am. Chem. Soc. 79 (1957) 1245.

7. Letsinger, R. L. and Lasco, R. J. Org. Chem. 21 (1956) 812.

8. Feuer, H., Bachman, G. B. and White, E. H. J. Am. Chem. Soc. 73 (1951) 4716.

9. Overberger, C. G., Byrd, N. R. and Mesbrobian, R. B. J. Am. Chem. Soc. 78 (1956) 1961.

10. Alder, K. and Niklas, H. Ann. 585 (1954) 81.

11. Puntambeker, S. V. and Zoellner, E. A. Org. Syntheses, Coll. vol. I, 2nd Ed. (1944) p. 524.

12. Mizzoni, R. H. and Spoerri, P. E. J. Am. Chem. Soc. 73 (1951) 1873.

13. Druey, J., Meier, K. and Eichenberger, K. Helv. Chim. Acta 37 (1954) 121.

14. Andersen, V. K. and Munch-Petersen, J. Acta Chem. Scand. 16 (1962) 947.

15. Wideqvist, S. Arkiv Kemi 2 (1950) 321.

Acta Chem. Scand. 16 (1962) No. 8

Received April 23, 1962. 